\title{
A literatura contra o Estado em 1968: política e exclusão em Clarice Lispector
}

JAime Ginzburg

Universidade de São Paulo

RESUMO: ESTE ESTUDO PROCURA EXAMINAR A ATITUDE DE CLARICE LISPECTOR EM CONTRARIEDADE À DITADURA MILITAR NO BRASIL. A "CARTA AO MINISTRO DA EDUCAÇÃO" EXPÕE UM FORTE CONFLITO ENTRE INSTITUIÇÕES EDUCACIONAIS E ESTUDANTES, E A ESCRITORA TOMA POSIÇÃO CONTRA A REPRESSÃO SOCIAL E A VIOLÊNCIA.

ABSTRACT: THIS STUDY TRIES TO EXAMINE CLARICE LISPECTOR'S ATTITUDE AGAINST DICTATORSHIP IN BRAZIL. HER "CARTA AO MINISTRO DA EDUCAÇÃO" PRESENTS A STRONG CONFLICT BETWEEN EDUCATIONAL INSTITUTIONS AND STUDENTS, AND THEN THE WRITER TAKES A POSITION AGAINST SOCIAL REPRESSION AND VIOLENCE.

PALAVRAS-CHAVE: CLARICE LISPECTOR - POLITICA - ESTUDANTES - UNIVERSIDADE KEY-WORDS: CLARICE LISPECTOR - POLITICS - STUDENTS - UNIVERSITY 
larice Lispector publicou o texto "Carta ao Ministro da Educação" no Jornal do Brasil, em 17 de fevereiro de 1968. O trabalho passou a ser mais difundido com sua inclusão no volume $A$ descoberta do mundo, compilação de 1984.

Embora esteja restrito ao espaço de dez parágrafos, o texto coloca importantes desafios para a análise e a interpretação. Mais do que isso, leva a questionar os critérios acadêmicos habituais de avaliação de textos literários, e enriquece de modo decisivo o amplo debate sobre as relações entre literatura e história recente no Brasil.

Embora ocupe um espaço regular no jornal dedicado à crônica, o texto se apresenta como uma carta, constituindo uma ambigüidade de gênero. Como carta, embora com interlocutor individualizado no título, o ministro da Educação, o texto ganha, no jornal, dimensão pública, com horizonte de interlocução tão amplo quanto o veículo permitir.

O objeto da discussão é a universidade brasileira. O texto teria como motivação imediata o edital publicado pelo MEC indicando que os concursos vestibulares seriam classificatórios. A posição da voz de enunciação articula perplexidade e indignação. Com a regulamentação dos vestibulares, o Ministério instituiu como categoria de política educacional os "excludentes", aqueles que não alcançam as notas necessárias para ingresso.

A reflexão proposta no texto de Clarice Lispector passa por diferentes níveis de envolvimento e empatia. Cabe destacar: um componente de submissão à autoridade, quando se refere à enunciadora como "simples escritora", em contraste com o ministro e o presidente; um depoimento, revelando que ela própria não teria tido direito à vaga, se fosse avaliada pelo critério de que não exerce a profissão em que se formou; uma atitude acusatória, tratando o procedimento ministerial como "crime"; uma postura piedosa, cativada por estudantes que choram e gastam seus recursos em livros caríssimos.

Os elementos biográficos referidos, como o depoimento sobre a formação universitária e as menções à conversa com uma estudante, podem levar à atribuição de um valor confessional ao texto. Isto é, a voz da enunciação seria de fato a de Clarice Lispector, e nada separaria a figura do autor de sua criação.

No entanto, como pretendemos expor adiante, esse texto se apresenta como uma configuração literária, com um aproveitamento de recursos polissêmicos e figuras de linguagem, em favor da acentuação do caráter provocador e polêmico das idéias. Se há veracidade nos aspectos biográficos, isso 
não é necessariamente relevante para a interpretação, isto é, consultar um biógrafo e indagar se a autora de fato conversou com uma estudante sobre o assunto na época não consiste em prerrogativa imprescindível para avaliar a relevância do texto.

Se for necessário trabalhar com padrões de classificação, esse texto de Clarice Lispector, mais do que uma crônica ou uma carta, se definiria como uma forma de literatura de testemunho. Trata-se de uma combinação singular de elementos históricos e literários, individuais e coletivos, em favor de uma posição de resistência. Cabe definir, no caso, resistência a quais forças históricas.

A discussão da universidade é assunto de teor político prioritário. Nesse período, como explica Betty de Oliveira, estão se estruturando as linhas de ação que virão, nos anos 1970, a compor a concepção tecnicista e modernizante da universidade brasileira, através das políticas de pós-graduação. A universidade passa, em larga medida, a ser instrumento do capitalismo multinacional, do imediatismo do mercado e da política econômica de índole militarista. Aparecem, na época, sinais de uma limitação intencional do espaço das humanidades, e de rigidez institucional contrária ao debate amplo de idéias.

O texto discute, ao colocar em questão o edital dos vestibulares, o problema da democratização da universidade. Ao propor dúvidas sobre os critérios para ingresso, critica o princípio da seleção naquilo que ele tem de excludente. Em vez de tratar o problema como quantitativo, como se faz em geral oficialmente, o texto contraria a reificação inerente ao sistema, e humaniza os excluídos, acentuando neles as manifestações de dor. O rigor da burocracia se expõe como fator de alienação e mascaramento da distorção social.

Para além e aquém da universidade, por dentro e por fora, age sobre ela e com ela o Estado. Em um ambiente que está a poucos meses do Ato Institucional n. 5, o governo brasileiro se caracteriza pela combinação de ideologias modernizantes e legitimação da truculência militarista.

É a esse Estado autoritário que o texto, com insuspeita ousadia, saudável atrevimento e atitude dissonante, propõe a imagem do criminoso. "Senhor ministro ou Presidente da República, impedir que jovens entrem em universidades é um crime”. Ao utilizar essa expressão, o texto toma partido dos excluídos, e, mais do que isso, ataca o sistema jurídico que os exclui, por meio da inversão de posições. O Estado, que tem o poder de direito, ganha a alcunha da transgressão, e os excluídos, destituídos de poder de transforma- 
ção, recebem no texto o tratamento de sujeitos interessados honestamente na universidade.

A indignação é acentuada com a referência ao vocábulo usado pelo discurso dominante: “[...]'excedentes' num país que ainda está em construção?! E que precisa com urgência de homens e mulheres que o construam?”. O problema dos estudantes não é apenas da instituição universitária, mas de um projeto de país. Este, de acordo com as imagens, sem ter chegado à plenitude, precisa, em sua precariedade, de forças de sustentação. A pontuação utilizada subverte o controle da disciplina de pensamento racional e atribui conotações emocionais ao impacto do problema.

Ambiguamente, embora assuma a modesta posição de uma "simples escritora", a voz de enunciação inteligentemente torna central para o debate o entendimento das palavras. A palavra "excedentes" é questionada, "crime" é considerada "palavra certa". A designação do interlocutor, de maneira dúbia e alternada, "senhor ministro ou senhor presidente", enfatiza a dificuldade de instaurar um debate quando não se pode designar com quem se pode falar, ou, ainda, quando nenhuma figura está imediatamente disponível para o debate. Indeterminar o interlocutor é sinalizar, conotativamente, que o debate está sugerido unilateralmente, e não concretizado por ambas as partes.

A construção discursiva de uma imagem imprecisa do interlocutor leva a questionar as condições de possibilidade do debate. Não apenas com quem se pode falar (com o ministro ou o presidente), mas quem pode ter essa iniciativa (pode fazer isso uma escritora?).

O texto elabora uma ligação entre os estudantes e a voz da enunciação.

"Esta medida impede qualquer ação judicial por parte dos que não são aproveitados, não impedindo no entanto que os alunos tenham o impulso de ir às ruas para reivindicar as vagas que lhes são negadas." (LISPECTOR, 1984: 93)

"Estou falando em nome de tantos que, simbolicamente, é como se o senhor chegasse à janela de seu gabinete de trabalho e visse embaixo uma multidão de rapazes e moças esperando seu veredicto.” (LISPECTOR, 1984: 94)

A presença dos estudantes como um grupo caracterizado como agente político permite observar o que Theodor Adorno considera um antagonismo social. Trata-se de um conflito entre o Estado e um grupo social, em que o segundo não se vê representado adequadamente pelo primeiro. $\mathrm{O}$ conflito de interesses 
é manejado de modo que os princípios do Estado se estabelecem à revelia dos interesses dos excluídos, caracterizando com precisão o que Florestan Fernandes entende como um processo social de autoritarismo. O antagonismo social, explica Adorno, reverte em um elemento constitutivo da forma. As diversas estratégias de indeterminação entre ficção e confissão, entre ministro e presidente, entre fluxo emocional e discurso argumentativo racional, criam tensões internas que, no processo de leitura, rompem com a percepção reificada e contribuem esteticamente para o choque, a percepção do sinistro na experiência social, mistura fantasmagórica de cotidiano e catástrofe, de normalidade disciplinar e estranheza monstruosa. Na violência física a serviço do Estado, encontramos a necessidade do estado de alerta, da preocupação com a ameaça. "E [os estudantes] nem poderiam sair à rua para uma passeata de protesto porque sabem que a polícia poderia espancá-los” (LISPECTOR, 1984: 95).

Se o texto se detém em algumas partes em um discurso argumentativo, com pretensões de objetividade e rigor lógico, escolhe para o final uma provocação: "Que estas páginas simbolizem uma passeata de protesto de rapazes e moças” (LISPECTOR, 1984: 95).

Ao escolher esse modo de finalizar, o texto se distancia do estatuto de objetividade, e pede para ser lido como se fosse uma passeata. Como a carta que deixa de ser contato entre dois indivíduos e se torna, como crônica, de interesse público, o texto deixa de se apresentar como experiência discursiva e pede para ser interpretado, conotativamente, como ação pública de contestação.

Ao fazer isso, o texto ganha complexidade estética. Ambiguamente, ele enuncia a inviabilidade prática do protesto nas ruas, por causa da violência estatal, e chama a imagem do protesto como manifestação contestatória. Com isso, torna seu próprio teor antagônico. Denotativamente, indica uma impossibilidade. Conotativamente, a contraria e propõe uma atitude libertária. Inclui internamente uma evidência do autoritarismo político, e reage a ele com "estas páginas", palavras que pedem estatuto de ação.

Em ruptura com a mimese tradicional e com as convenções objetivas do jornalismo, o texto se distancia do realismo. A realidade não pode ser representada diretamente, porque na realidade a passeata não poderia ocorrer, na realidade a conversa com o presidente não ocorreria, sob o risco de violência, prisão, tortura e morte. Dos estudantes, da escritora que com eles se solidariza. 
O texto por isso constrói uma imagem da realidade antagônica à repressão. Uma imagem em que a conversa com o presidente - incluindo a palavra "crime" - pode ser sugerida, e em que a passeata de protesto dos estudantes acontece, sem o impedimento da repressão policial. Essa imagem, não sem contradição, não quer apresentar a realidade social tal como ela de fato é. Ela encena condições de debate e polemização, interditas pelo regime autoritário. A relação do texto com o seu contexto não é identificatória, é negativa. Trata-se de crítica cultural no sentido adorniano: examinar o processo histórico conflitivo com distanciamento, mas também com inserção, assumindo ser parte integrante do processo.

Os estudantes são descritos como dotados de "impulso de ir às ruas". O texto propõe que o ministro ou presidente veja em sua janela "uma multidão de rapazes e moças esperando seu veredicto”. São imagens de expectativa social de mudança política. A cena da multidão não pode ser vista como documental ou realista, ela pede interpretação alegórica.

O texto escolhe refletir não apenas sobre a realidade já dada, mas sobre uma realidade em processo, em construção, em que as expectativas de mudança são centrais. A leitura alegórica é oportuna, pensando com Jeanne-Marie Gagnebin, para salientar o que há na experiência de fragmentário, destruído, inorgânico e inconsistente.

A imagem do Brasil construída não é a de uma nação totalizada, integrada e harmoniosa, mas de um espaço conflituoso, em que as lideranças políticas estão em descompasso com a sociedade que deveriam representar. $\mathrm{O}$ texto de Clarice Lispector propõe ser lido como crítica desse descompasso. Faz isso não apenas em terceira pessoa, mas utilizando a primeira e segunda pessoas discursivas. Tomando como interlocutor a autoridade do Estado e como referência metonímica as vozes silenciadas dos estudantes que não podem sair em protesto, o texto se torna espaço constituído dentro do descompasso, manifestação de inconformidade construída ambiguamente, entre o que pode ser dito e o que está interdito.

\section{Referências Bibliográficas}

ADORNO, Theodor. Crítica cultural e sociedade. In: Prismas: crítica cultural e sociedade. Trad. Augustin Wernet e Jorge Brito de Almeida. São Paulo: Ática, 1998. 
Teoria Estética. Trad. Artur Morão. Lisboa: Martins Fontes, 1988.

FERNANDES, Florestan. Apontamentos sobre a teoria do autoritarismo. São Paulo: Hucitec, 1979.

GAGNEBIN, Jeanne-Marie. Origem da alegoria, alegoria da origem. Folha de S. Paulo, São Paulo, 9 dez. 1984.

GARCIA, Gustavo V. La literatura testimonial latinoamericana. Madrid: Pliegos, 2003. LISPECTOR, Clarice. A descoberta do mundo. Rio de Janeiro: Nova Fronteira, 1984.

OLIVEIRA, Betty Antunes. O estado autoritário brasileiro e o ensino superior. São Paulo: Cortez/Autores Associados, 1983. 